\title{
Bovine antibody-based oral immunotherapy for reduction of intragastric Helicobacter pylori colonization: A randomized clinical trial
}

\author{
CM den Hoed $\mathrm{MD}^{1,2}$, AC de Vries MD PhD ${ }^{1,2}$, PBF Mensink MD PhD ${ }^{1,2}$, CM Dierikx MSC PhDD, \\ H Suzuki MD PhD ${ }^{3}$, L Capelle MD PhD ${ }^{1}, \mathrm{H}$ van Dekken MD PhD ${ }^{4}$, R Ouwendijk MD PhD ${ }^{5}$, EJ Kuipers MD Prof ${ }^{1,2,6}$
}

CM den Hoed, AC de Vries, PBF Mensink, et al. Bovine antibody-based oral immunotherapy for reduction of intragastric Helicobacter pylori colonization: A randomized clinical trial. Can J Gastroenterol 2011;25(4):207-213.

BACKGROUND: Antibiotic-based regimens are frequently used for the treatment of Helicobacter pylori infection. These regimens fail to eradicate $\mathrm{H}$ pylori in $15 \%$ to $40 \%$ of patients, primarily due to antimicrobial resistance and insufficient patient compliance. Effective prevention and eradication of $\mathrm{H}$ pylori by passive immunization with orally administered bovine antibodies has been demonstrated in animal studies, and may serve as an alternative therapy in humans.

OBJECTIVE: To study the efficacy and safety of orally administered bovine anti-H pylori antibodies for the reduction of intragastric bacterial load and eradication of $H$ pylori in humans.

METHODS: Dairy cows were immunized against $H$ pylori. After confirmation of the presence of anti-H pylori antibodies in the milk, the milk was subsequently processed into a whey protein concentrate (WPC). In a prospective, double-blind, placebo-controlled randomized clinical trial, $\mathrm{H}$ pylori-infected subjects were randomly assigned to treatment with the WPC preparation or placebo. Study medication was continued for 28 days; subjects were followed-up for 56 days.

RESULTS: Of the 30 subjects included, 27 completed the protocol. Of these 27 evaluable subjects, 14 were treated with WPC and 13 with placebo. There was no significant difference in urea breath test decrease between the WPC- and placebo-treated group $(\mathrm{P}=0.75)$. $\mathrm{H}$ pylori-associated gastritis and density were not significantly reduced in either group after treatment $(\mathrm{P}>0.05$ for all).

CONCLUSION: Bovine antibody-based oral immunotherapy appears to be safe, but does not significantly reduce intragastric $H$ pylori density in humans. Further studies are needed to determine whether WPC treatment has additional value to conventional antibiotic treatment for $H$ pylori.

Key Words: H pylori; Eradication treatment; Immunotherapy; Gastritis

Uelicobacter pylori infection causes chronic active gastritis in virtu1 ally all infected patients and is associated with an increased risk of peptic ulcer disease, mucosa-associated lymphoid tissue lymphoma and gastric cancer (1-3). Therefore, $H$ pylori eradication therapy is frequently prescribed in patients in whom the presence of $\mathrm{H}$ pylori colonization has been confirmed. The current European guidelines state that a positive $H$ pylori test is an indication for eradication treatment (4). Such treatment regularly consists of the combination of two to three antimicrobial drugs in combination with a proton pump inhibitor (PPI). However, treatment failure occurs in up to $40 \%$ of patients, primarily due to bacterial resistance and insufficient patient compliance, among others, and as a result of gastrointestinal side effects (Table 1) (5,6). Consequently, new therapeutic strategies with
Une immunothérapie orale à base d'anticorps bovin pour réduire la colonisation intragastrique de Helicobacter pylori : un essai clinique aléatoire

HISTORIQUE : On utilise souvent des antibiotiques pour traiter les infections à Helicobacter pylori. Chez $15 \%$ à $40 \%$ des patients, ces antibiotiques n'éradiquent pas le $\mathrm{H}$ pylori, surtout en raison d'une antibiorésistance et d'une observance insuffisante de la part des patients. Des études auprès d'animaux ont démontré une prévention et une éradication efficaces du $\mathrm{H}$ pylori par immunisation passive au moyen d'anticorps bovins administrés par voie orale, ce qui pourrait constituer une autre thérapie chez les humains.

OBJECTIF : Étudier l'efficacité et l'innocuité de l'administration d'anticorps anti-H pylori pour réduire la charge bactérienne intragastrique et l'éradication du $H$ pylori chez les humains.

MÉTHODOLOGIE : Des vaches laitières ont été immunisées contre le $\mathrm{H}$ pylori. Après confirmation de la présence d'anticorps anti-H pylori dans leur lait, ce lait a été transformé en concentré de protéine de lactosérum (CPL). Dans un essai clinique à double insu aléatoire et contrôlé contre placebo, des personnes infectées par le H pylori ont été réparties au hasard entre le traitement à l'aide de la préparation de CPL et un placebo. L'étude du médicament s'est poursuivie pendant 28 jours, et les sujets ont été suivis pendant 56 jours.

RÉSULTATS : Des 30 sujets participants, 27 ont terminé le protocole. De ces 27 sujets évalués, 14 ont été traités par CPL, et 13, par placebo. On n'a constaté aucune différence significative de diminution du test respiratoire à l'urée au sein du groupe traité par CPL et de celui traité par placebo $(\mathrm{P}=0,75)$. La gastrite et la densité associées au $\mathrm{H}$ pylori n'avaient pas diminué de manière significative dans les deux groupes après le traitement ( $\mathrm{P}>0,05$ dans tous les cas).

CONCLUSION : Une immunothérapie orale à l'anticorps bovin semble être sécuritaire, mais elle ne réduit pas la densité intagastrique de $H$ pylori de manière significative chez les humains. D'autres études s'imposent pour déterminer si un traitement au CPL a une valeur supplémentaire par rapport à l'antibiothérapie classique du $\mathrm{H}$ pylori.

broader approaches to treating, suppressing or possibly preventing $H$ pylori infections to circumvent problems with drug resistance and side effects are required.

Passive immunization with orally administered antibodies against $\mathrm{H}$ pylori may constitute one of these alternatives. This approach has been shown to be effective in the prevention and treatment of a variety of pathogens such as Candida albicans, rotavirus, Clostridium difficile and Campylobacter jejuni (7-11). Animal studies have shown that bovine antibodies against $H$ pylori reduce bacterial load and that $H$ pylori infection can thereby be prevented and even eradicated $(12,13)$. In humans, breastfeeding seems to protect infants from early acquisition of $\mathrm{H}$ pylori, also suggesting that passive delivery of immunoglobulin (Ig) A antibodies affect $H$ pylori colonization (14).

Departments of ${ }^{1}$ Gastroenterology; ${ }^{2}$ Hepatology, Erasmus University Medical Center, Rotterdam, The Netherlands; ${ }^{3}$ Department of Internal Medicine,

Keio University School of Medicine, Tokyo, Japan; ${ }^{4}$ Department of Pathology, Erasmus University Medical Center; ${ }^{5}$ Department of Gastroenterology

and Hepatology, Ikazia Hospital, Ziekenhuis; ${ }^{6}$ Department of Internal Medicine, Erasmus University Medical Center, Rotterdam, The Netherlands

Correspondence: Dr CM den Hoed, Department of Gastroenterology and Hepatology, Erasmus MC, Room Ca 409, PO Box 2040,

3000 CA Rotterdam, The Netherlands. Telephone 0031-10-7033042, fax 0031-10-7032908, e-mail c.denhoed@erasmusmc.nl

Received for publication January 12, 2010. Accepted October 6, 2010 
TABLE 1

Eradication rates, and first-, second-, third- and fourth-line treatments for Helicobacter pylori infection

\begin{tabular}{|c|c|c|c|c|}
\hline $\begin{array}{l}\text { Author } \\
\text { (reference), year }\end{array}$ & Country & Study type & Treatment & $\begin{array}{l}\text { Eradication } \\
\text { rate, } \%\end{array}$ \\
\hline \multirow{3}{*}{$\begin{array}{l}\text { Rokkas et al (41), } \\
2009\end{array}$} & \multirow[t]{3}{*}{ Greece } & \multirow{3}{*}{$\begin{array}{l}\text { Prospective } \\
(\mathrm{n}=540)\end{array}$} & First line: Omeprazole + amoxicillin + clarithromycin & 76 \\
\hline & & & Second line: Omeprazole + bismuth + metronidazole + tetracycline & 73 \\
\hline & & & Third line: Omeprazole + amoxicillin + levofloxacin & 70 \\
\hline \multirow{5}{*}{$\begin{array}{l}\text { Hojo et al (42), } \\
2001\end{array}$} & \multirow[t]{5}{*}{ Japan } & \multirow[t]{5}{*}{ Meta-analysis } & Second-line treatment: & \\
\hline & & & Proton pump inhibitor + 1 antimicrobial agent & 45.8 \\
\hline & & & Proton pump inhibitor +2 antimicrobial agents & 69.8 \\
\hline & & & Ranitidine-bismuth +2 antimicrobial agents & 80.2 \\
\hline & & & Proton pump inhibitor + bismuth +2 antimicrobial agents & 75.8 \\
\hline \multirow{4}{*}{$\begin{array}{l}\text { Seppälä et al (43), } \\
2000\end{array}$} & \multirow[t]{4}{*}{ Finland } & \multirow{4}{*}{$\begin{array}{l}\text { Prospective } \\
(\mathrm{n}=644)\end{array}$} & First-line treatment of choice of treating physician: & 81 \\
\hline & & & $\begin{array}{l}\text { Second line: Bismuth + metronidazole }+ \text { amoxicillin/tetracycline or omeprazole }+ \text { bismuth } \\
+ \text { metronidazole }+ \text { amoxicillin/tetracycline or triple therapy* based on susceptibility test }\end{array}$ & 58 \\
\hline & & & Third line: One of the treatments mentioned under second line & 76 \\
\hline & & & Fourth line: Another one of the treatments mentioned under second line & 100 \\
\hline \multirow[t]{2}{*}{$\begin{array}{l}\text { Pontone et al (44), } \\
2010\end{array}$} & \multirow[t]{2}{*}{ Italy } & \multirow[t]{2}{*}{$\operatorname{RCT}(n=84)$} & $\begin{array}{l}\text { Sequential therapy: Lansoprazolen }+ \text { amoxicillin for } 5 \text { days and lansoprazole + clarithromycin } \\
+ \text { metronidazole for an additional } 5 \text { days }\end{array}$ & 83 \\
\hline & & & Rescue therapy: Lansoprazole + levofloxacin + amoxicillin & 100 \\
\hline \multirow{3}{*}{$\begin{array}{l}\text { Kearny and Brousal } \\
(45), 2000\end{array}$} & \multirow{3}{*}{$\begin{array}{l}\text { United } \\
\text { States }\end{array}$} & \multirow[t]{3}{*}{$\mathrm{RCT}(\mathrm{n}=224)$} & Bismuth + metronidazole + tetracycline & 81 \\
\hline & & & Lansoprazole + metronidazole + clarithromycin & 90 \\
\hline & & & Proton pump inhibitor + bismuth + metronidazole + tetracycline & 87 \\
\hline \multirow[t]{3}{*}{$\begin{array}{l}\text { Vaira et al (46), } \\
2007\end{array}$} & \multirow[t]{3}{*}{ Italy } & \multirow[t]{3}{*}{$\operatorname{RCT}(n=300)$} & $\begin{array}{l}\text { Proton pump inhibitor }+ \text { amoxicillin ( } 5 \text { days) and proton pump inhibitor + clarithromycin } \\
+ \text { tinidazole ( } 5 \text { days) }\end{array}$ & 89 \\
\hline & & & OR & \\
\hline & & & Proton pump inhibitor + clarithromycin + amoxicillin (10 days) & 77 \\
\hline
\end{tabular}

*Triple therapy: Proton pump inhibitor plus two different antibiotics. RCT Randomized controlled trial

H. pylori-lysate

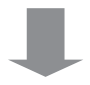

Immunization cows

Milking during lactation period

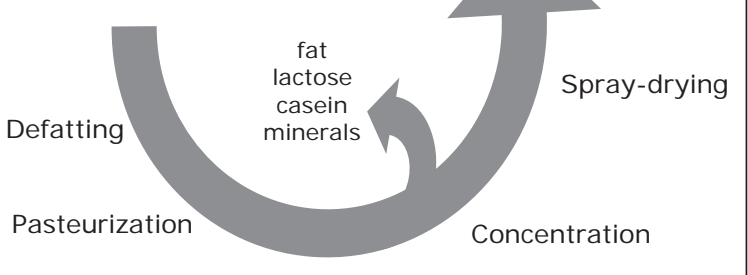

Figure 1) Whey protein concentrate (WPC) preparation. H. pylori Helicobacter pylori

The primary underlying mechanism is probably based on inhibition of adherence of $\mathrm{H}$ pylori to the gastric mucosa by specific antibodies to the main $H$ pylori surface-binding antigens (15). However, results of clinical studies on the effect of specific anti-H pylori antibodies are scarce. The studies that are available have reported conflicting results (16-20). While two studies did not demonstrate any effect of treatment with bovine antibodies $(16,18)$, three others reported that treatment with bovine antibodies could eradicate $H$ pylori infection in all patients $(19,20)$ or decrease $H$ pylori colonization density and the extent of gastritis (17). None of these studies were, however, placebo controlled. Therefore, we performed a randomized, placebo-controlled clinical study to evaluate the efficacy and safety of specific anti-H pylori polyclonal bovine IgA antibodies for the reduction of intragastric bacterial load and gastritis activity in humans.

\section{METHODS}

Study medication: Immune whey protein concentrate preparation A polyclonal antibody-enriched immune whey protein concentrate (WPC-80 [80\% protein]) was prepared from milk collected from cows immunized with whole antigen lysates of eight clinical H pylori isolates.

The immunization of six dairy cows comprised repeated nasal (mucosal every two weeks) and supramammary lymph node administration (percutaneous once every month). After immunization, the presence of polyclonal secretory component (sIgA) anti-H pylori antibodies in the milk was confirmed by ELISA. Immune WPC- 80 was prepared using standard milk industry techniques (Figure 1). The whey fraction was pasteurized, concentrated by ultra filtration and spraydried to yield the final whey powder. One gram of the final enriched WPC preparation contained approximately $80 \%$ protein, of which approximately $20 \%$ consisted of Ig, and was completely free of lactose. Inhibition of the adherence of $\mathrm{H}$ pylori to gastric tissue by specific antibodies in the WPC-80 preparation was demonstrated in vitro using fluorescently labelled $\mathrm{H}$ pylori. The adherence of $\mathrm{H}$ pylori in the presence of phosphate-buffered saline/bovine serum albumin and nonspecific antibodies was used as the control.

\section{Study design}

The present study was designed to be a double-blind, placebo-controlled trial (Figure 2). Adult $\mathrm{H}$ pylori-positive subjects (18 years of age and older), as demonstrated by both a positive ${ }^{13} \mathrm{C}$-urea breath test and histopathology confirming $\mathrm{H}$ pylori gastritis were eligible for inclusion (Figure 3). Thirty $\mathrm{H}$ pylori-positive subjects were randomly assigned to either immune WPC treatment (15 subjects) or placebo (15 subjects). Randomization occurred within blocks containing four subjects each, according to a randomization table designed by Department of Statistics at the University of California, Los Angeles (USA). Consecutive eligible patients were included after informed consent, and a coded study number was assigned to each patient. 


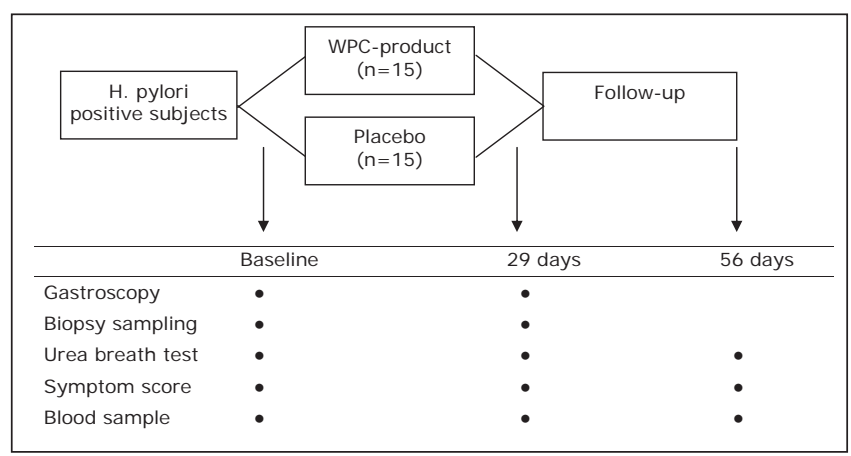

Figure 2) Study design. H. pylori Helicobacter pylori; WPC Whey protein concentrate

Treatment with $\mathrm{H}_{2}$-blockers or PPIs was allowed, provided that the doses were stable at least two weeks before the start of the study medication, including the time of the ${ }^{13} \mathrm{C}$-urea breath test and sampling of gastric biopsies, and remained stable during the study period. Subjects who underwent previous treatment for $\mathrm{H}$ pylori infection with standard therapy were also included. Exclusion criteria were as follows: lactose intolerance, pregnancy or lactation, active peptic ulcer disease, malignancy, significant systemic comorbidity and use of antibiotics within four weeks before the start of the study.

All subjects received $2.5 \mathrm{~g}$ of immune WPC or placebo, to be taken three times daily during meals for 28 days. The medications had identical appearances. Adherence to study medication was monitored by recording the number of empty medication sachets and conducting interviews. The follow-up period was 56 days.

Gastroscopy with biopsy sampling was performed at baseline and at the end of treatment (at 29 days). During gastroscopy, two antral and two corpus biopsies were obtained for histological assessment. In addition, one antral and one corpus biopsy were obtained for $\mathrm{H}$ pylori culture. ${ }^{13} \mathrm{C}$-urea breath tests and serological tests were performed at the start of the study, after completion of study medication and at the end of follow-up. Serological evaluation comprised hematological and biochemical markers, and serum levels of gastrin, pepsinogen I, pepsinogen II and $\mathrm{H}$ pylori-specific IgG. In addition, serum anticytotoxin gene A ( CagA) protein IgG antibodies were evaluated at the start of the study.

Dyspeptic symptoms including heartburn, acid regurgitation and epigastric discomfort were evaluated using a validated questionnaire. All items were rated according to seven criteria of the Gastrointestinal Symptom Rating Scale $(21,22)$. The questionnaires were completed before treatment, each week during treatment, just after completion of treatment and at 56 days. In addition, all adverse events during follow-up were recorded.

The Institutional Review Board of the Erasmus University Medical Centre (Rotterdam, The Netherlands) approved the study protocol. All subjects provided informed written consent before enrollment.

Histological and culture methods

Gastric biopsy specimens were fixed in buffered formalin and embedded in paraffin. Hematoxylin-eosin stained sections were used for standard histological evaluation. A single, expert gastrointestinal pathologist performed all histological assessments. The pathologist was blinded to the timing of biopsies, treatment assignment, and clinical and endoscopic data. The samples were assessed according to the updated Sydney classification. The sections were graded for $\mathrm{H}$ pylori density, polymorphonuclear neutrophil activity, mononuclear cells, gastric glandular atrophy and intestinal metaplasia. All parameters were scored using the following four-point scale: absent $=0$, ild $=1$, moderate $=2$ and severe $=3$. Culture of $H$ pylori was performed under microaerophilic conditions (5\% oxygen, 10\% carbon dioxide and $85 \%$ nitrogen) using blood agar plates (Dent-plates, Biotrading, The Netherlands).

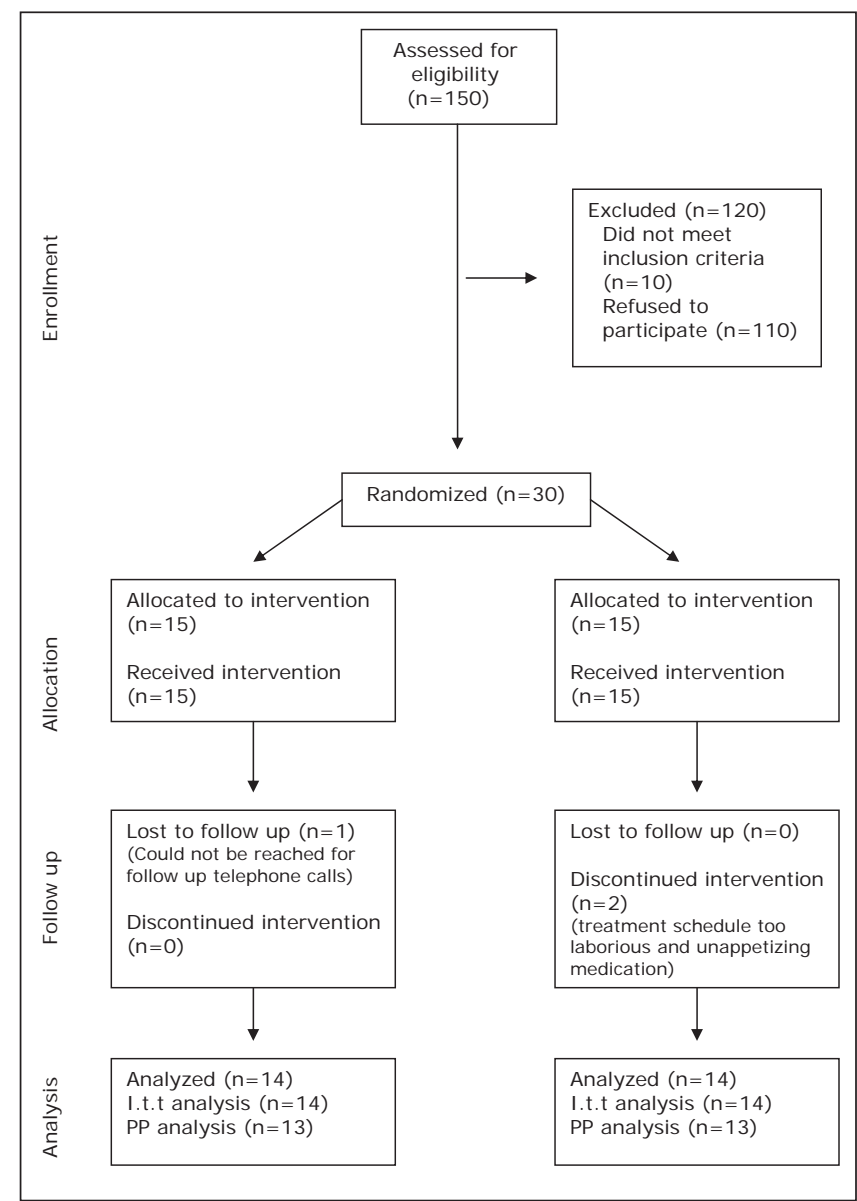

Figure 3) Consort diagram. I.t.t Intention to treat; PP Per protocol

\section{Data analysis}

The efficacy of the WPC preparation to reduce intragastric H pylori bacterial load was evaluated according to the reduction in intragastric urease activity measured by ${ }^{13} \mathrm{C}$-urea breath tests and reduction of bacterial colonization, as well as acute gastritis quantified by histological assessments according to the updated Sydney system. The number of patients was sufficient to demonstrate a $30 \%$ difference in the above mentioned parameters, with a predictive power of $90 \%$. An intention to treat and per-protocol analysis were performed comparing the immune WPC-80 treatment group and placebo group. Statistical analysis was performed using Wilcoxon's rank sum test for changes from baseline to end of treatment for histological severity grades of gastritis. A subgroup analysis of patients receiving acid-suppressive drugs was performed. A two-sided $\mathrm{P}<0.05$ was considered to be statistically significant. Power was not calculated due to the explorative nature of the study.

\section{RESULTS}

\section{Participants}

In total, 30 subjects were included and randomly assigned to the placebo- or WPC-treated group. One patient in the WPC group was lost to follow-up immediately after randomization before the start of the study medication. Two patients in the placebo group discontinued the study medication within two weeks - one due to the intensity of the treatment regimen, the other due to the unappetizing flavour of the placebo; therefore, follow-up data on these patients were not available. 
TABLE 2

Baseline epidemiological, histological, serological and ${ }^{13} \mathrm{C}$ urea breath test results of both treatment groups

\begin{tabular}{|c|c|c|c|}
\hline & \multicolumn{2}{|c|}{ Treatment group } & \multirow[b]{2}{*}{$\mathbf{P}$} \\
\hline & WPC (n=14) & Placebo $(n=15)$ & \\
\hline Sex, n (male/female) & $5 / 9$ & $9 / 6$ & 0.27 \\
\hline Age, years (mean $\pm S D$ ) & $44.7 \pm 14.0$ & $51.3 \pm 14.4$ & 0.22 \\
\hline Range & $25-67$ & $25-75$ & \\
\hline \multicolumn{4}{|l|}{ Acid-suppressant use, $\mathrm{n}$} \\
\hline Proton pump inhibitor & 4 & 5 & 1.0 \\
\hline $\mathrm{H}_{2}$-blocker & 3 & 2 & \\
\hline Previous eradication treatment, $\mathrm{n}$ & 6 & 6 & 1.0 \\
\hline \multicolumn{4}{|l|}{ Country of birth, $n$} \\
\hline The Netherlands & 8 & 6 & 0.81 \\
\hline Turkey & 3 & 5 & \\
\hline Morocco & 1 & 1 & \\
\hline Other & 2 & 3 & \\
\hline \multicolumn{4}{|l|}{ Histological findings } \\
\hline \multicolumn{4}{|l|}{ Antrum } \\
\hline H. pylori colonization & $1.86(1.03)$ & $1.67(1.05)$ & 0.63 \\
\hline Activity & $1.14(0.77)$ & $1.47(0.92)$ & 0.31 \\
\hline Inflammation & $2.28(0.47)$ & $2.07(0.80)$ & 0.37 \\
\hline \multicolumn{4}{|l|}{ Corpus } \\
\hline H. pylori colonization & $1.0(0.82)$ & $1.33(0.82)$ & 0.29 \\
\hline Activity & $0.92(0.76)$ & $0.80(0.68)$ & 0.66 \\
\hline Inflammation & $1.54(0.66)$ & $1.73(0.59)$ & 0.42 \\
\hline $\begin{array}{l}\text { Premalignant gastric lesions, } \\
\mathrm{n}(\%)\end{array}$ & $1(7.1)$ & $4(26.7)$ & 0.33 \\
\hline $\begin{array}{l}\text { Urea breath test, } \\
\text { mean delta value } \pm \mathrm{SD}\end{array}$ & $24.2 \pm 17.4$ & $23.8 \pm 16.3$ & 0.95 \\
\hline $\begin{array}{l}\text { H. pylori IgG, mg/mL } \\
\quad(\text { mean } \pm \mathrm{SD})\end{array}$ & $202 \pm 178$ & $152 \pm 127$ & 0.40 \\
\hline CagA positive, n (\%) & $9(64)$ & $11(73)$ & 0.43 \\
\hline Gastrin, ng/L (mean \pm SD) & $20.7 \pm 24$ & $24 \pm 25$ & 0.73 \\
\hline $\begin{array}{l}\text { Pepsinogen I, ng/mL } \\
\text { (mean } \pm \mathrm{SD})\end{array}$ & $163 \pm 90.0$ & $147 \pm 61$ & 0.58 \\
\hline Pepsinogen II & $14.2 \pm 3.7$ & $15.9 \pm 4.3$ & 0.85 \\
\hline $\begin{array}{l}\text { Pepsinogen ratio } \mathrm{I} / \mathrm{I}, \\
\text { mean } \pm \mathrm{SD}\end{array}$ & $16.5 \pm 4.9$ & $17.0 \pm 8.8$ & 0.86 \\
\hline
\end{tabular}

CagA Cytotoxin-associated gene A; H. pylori Helicobacter pylori; Ig Immunoglobulin; WPC Whey protein concentrate

Baseline characteristics

Following randomization, 14 patients were treated with the WPC-80 preparation and 15 patients with placebo. The groups were similar with respect to several baseline characteristics (Table 2). At baseline, 14 (48\%) patients used acid-suppressive drugs; these patients were equally distributed between both treatment arms $(\mathrm{P}=1.00)$. Infection with CagA-positive $H$ pylori strains was present in nine $(64 \%)$ patients included in the WPC-80 group, compared with 11 (73\%) patients in the placebo group $(\mathrm{P}=0.43)$. Premalignant gastric lesions, atrophic gastritis and intestinal metaplasia were found in one patient in the WPC group and in four patients in the placebo group $(\mathrm{P}=0.33)$.

\section{H pylori bacterial load}

In the intention to treat analysis, no significant differences between groups were found in urea breath test results at baseline or follow-up and, similarly, in the effect of treatment on urea breath test results ( $P>0.05$ for all) (Table 3). Moreover, no significant differences were observed between subgroups within treatment arms $(\mathrm{P}=0.57)$, or in patients with or without simultaneous use of acid-suppressive drugs $(\mathrm{P}=0.35)$.

Histological assessment did not demonstrate an effect of active or placebo treatment on acute gastritis and the $H$ pylori colonization scores in the antrum (Figures 4 and 5). The $H$ pylori colonization scores in the corpus even seemed to increase after treatment with WPC-80 ( $\mathrm{P}=0.03)$ (Figure 5). In addition, no significant differences in outcome were observed between treatment groups. Subgroup analysis of patients with or without simultaneous use of acid-suppressive drugs showed no significant differences $(P>0.05$ for all). In one patient, $H$ pylori eradication was achieved after concomitant use of the WPC preparation and a one-day course of metronidazole; this patient was not included in the per-protocol analysis. Twenty-six patients were considered in the per-protocol analysis, which did not demonstrate an effect of the WPC-80 or placebo treatment. No differences were obtained using the per-protocol analysis versus the intention to treat analysis $(\mathrm{P}>0.05$ for all).

\section{Serology}

Comparison of anti-H pylori $\operatorname{IgG}$ antibody levels did not demonstrate any differences between the WPC-80 group and the placebo group at day $29(\mathrm{P}=0.63)$ nor at day $56(\mathrm{P}=0.33)$ (Table 2). No significant differences with respect to the mean reduction in serum $H$ pylori antigen concentration at day $0(\mathrm{P}=0.33)$ and day $56(\mathrm{P}=0.54)$ in the WPC-80 group and the placebo group, respectively, were found.

No differences were demonstrated between the WPC-80 group and the placebo group when the mean values of gastrin, pepsinogen I and pepsinogen II levels, and the pepsinogen ratio at baseline at day 29 or day 56 were compared. The levels of these parameters did not change significantly within either group during follow-up, nor were there significant changes between groups in this respect (Table 3 ).

\section{Safety}

Twenty-seven subjects completed the study - 14 in the WPC group and 13 in the placebo group. None of the patients experienced adverse effects due to WPC-80 treatment, and the preparation was well tolerated. No significant differences were identified in the quality of life scores of the WPC-80 group compared with the placebo group on days 7, 14, 21, 28 and 56 ( $P>0.05$ for all). Quality of life scores remained stable during the course of the study in both groups.

TABLE 3

Urea breath test and serology results in both treatment groups at day 29 and day 56

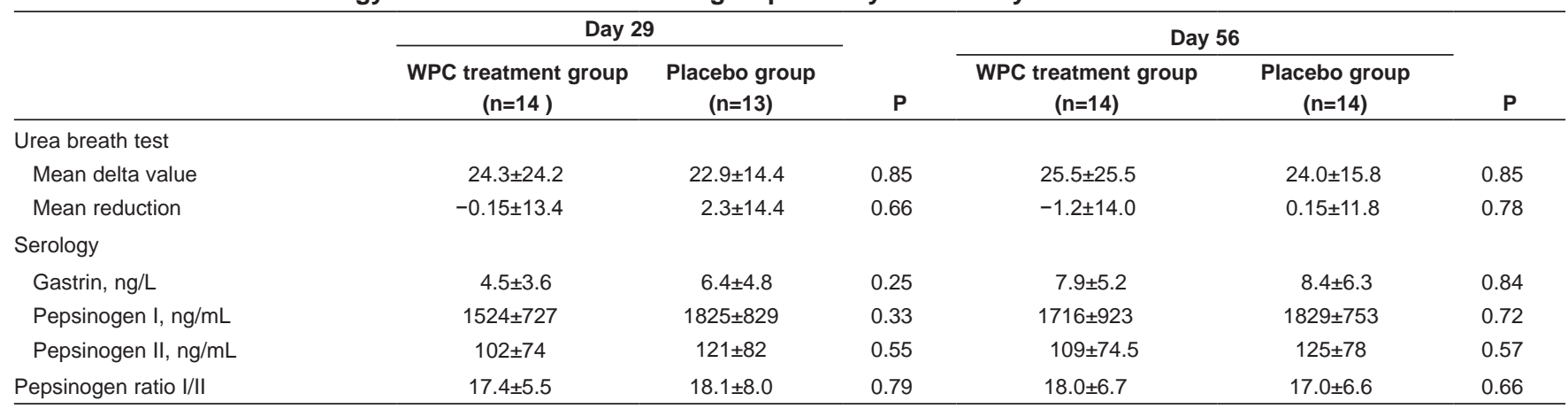

Data presented as mean \pm SD unless otherwise indicated. WPC Whey protein concentrate 


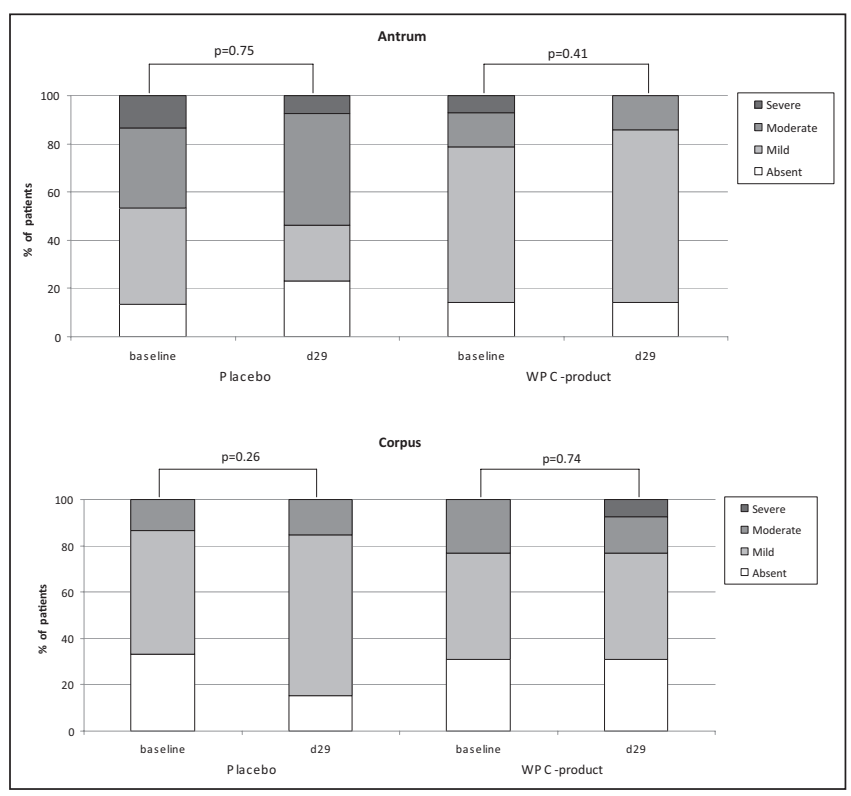

Figure 4) Histological grade of active gastritis in antrum and corpus in patients randomly assigned to placebo or whey protein concentrate (WPC) preparation. d Day

Analysis of general blood test parameters revealed no significant changes in either treatment group, nor were there changes in serum liver enzymes or additional serological parameters (eg, hemoglobin, leukocytes, etc) ( $\mathrm{P}>0.05$ for all).

\section{DISCUSSION}

The present clinical study did not demonstrate a positive effect on $\mathrm{H}$ pylori-associated gastritis or colonization density following administration of a polyclonal antibody-enriched (sIgA) WPC-80 preparation in humans. No significant reduction was demonstrated in urea breath test levels determined on days 0, 29 and 56. Treatment in either arm had no effects on serum $H$ pylori IgG antibody titres, gastrin, pepsinogen I and II levels, or on the pepsinogen I/II ratio. Correcting for the use of PPIs did not influence differences in the outcomes. However, we demonstrated that WPC-80 was well tolerated and did not cause any adverse effects or a decrease in quality of life scores.

$H$ pylori infection is widespread in humans. Although it can be cured by antimicrobial therapy, large-scale use of antibiotics has led to the increasing emergence of antibiotic-resistant strains. Furthermore, side effects of current eradication treatments, although partially preventable by the coadministration of probiotics, limit their efficacy by induction of early treatment withdrawal (23). This has prompted investigators to focus on several alternatives. These alternatives must be effective; however, considerations such as costs, side effects and ease of administration should also be taken into account.

Because previous studies have shown protection against early acquisition of $H$ pylori through breastfeeding in breastfed infants (14), the concept of passive immunization (ie, mimicking mechanisms of natural protection) as a logical approach has emerged. An in vitro study conducted in 2001 confirmed the possible effectiveness of antibodies by showing a complement-dependent bactericidal effect of WPC with $H$ pylori-specific antibodies. The WPC prevented adherence of $\mathrm{H}$ pylori to the gastric mucosa $(24,25)$. In addition, an early clinical study in 1991 (19) demonstrated H pylori eradication in 20 patients receiving an $\mathrm{H}$ pylori-specific bovine Ig. The outcomes of more recent studies with $H$ pylori-infected patients $(16-18,20)$ have shown modest, albeit encouraging, results. However, one of these studies was open labelled (18) and used a treatment period of only two days, while two others included children only $(16,17)$. Furthermore, the methodology of the other studies were unclear $(16-18,20)$.

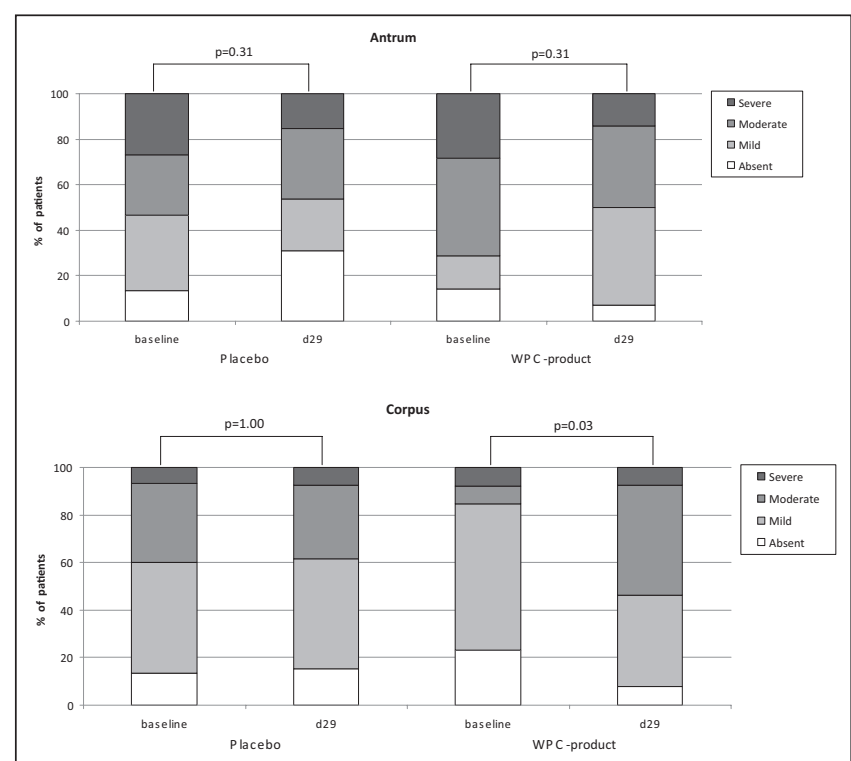

Figure 5) Histological grade of Helicobacter pylori colonization in antrum and corpus in patients randomly assigned to placebo or whey protein concentrate (WPC) preparation. d Day

A possible limitation of the present analysis was the size of the study population, which may have been too small to demonstrate significant reductions in intragastric bacterial load or gastritis activity by treatment with bovine antibody-based oral immunotherapy. Furthermore, because the optimal length of treatment remains unknown, our study may have been limited by the relatively short duration of WPC-80 treatment. Previously conducted studies (15) used a duration of between two days and four weeks. However, given the total absence of any effect after four weeks in the population studied, we consider it unlikely that an increase in the study population or prolongation of treatment with the same dose would have led to measurable changes.

We cannot exclude the possibility that an increase in dose and/or dosing frequency would have led to an effect on $\mathrm{H}$ pylori colonization. The dose and administration frequency used in the present study were chosen on the basis of previous experience with similar products, particularly those against $\mathrm{C}$ difficile (11). Finally, our study may have been limited by the fact that intragastric antibody availability has yet to be clarified (25). Therefore, future research in human subjects is necessary to obtain additional information regarding the optimal antibody dose, frequency of administration and ratio.

The strengths of the present study were the strictly defined outcome parameters, the double-blinded design with repeated follow-up assessments and the exclusion of a possible concomitant antibiotic effect. Except for one subject, all patients completed the four-week treatment course and no adverse effects linked to treatment were identified.

Current research has focused on several alternatives to replace antibiotic eradication therapy. In contrast to our study of bovinederived IgA antibodies, Japanese researchers have described positive effects of egg yolk-derived IgY, demonstrating a decrease in urea breath test parameters in patients treated with $\operatorname{IgY}(26,27)$. Similar studies examining the natural antimicrobial properties of colostrum and egg yolk have focused on the possible use of lactoferrin and lysozyme, which are also components of the humoral immune reaction. Positive effects of bovine antibodies were demonstrated in vitro and in animal models, but conflicting results were obtained in human studies (28). Some studies described a suppressive effect of lactoferrin and lysozyme on H pylori colonization $(28,29)$, while others even described an increase in H pylori growth and gastric inflammation (30). However, supplementing current eradication therapy with lactoferrin appears to increase eradication rates and could be helpful in patients who fail 
eradication therapy. Furthermore, addition of lactoferrin may also have a positive impact on $H$ pylori therapy-related side effects (31).

Several studies examining the effects of probiotics, especially in combination with current therapies, have been conducted (23,32-35), and have demonstrated positive effects and trends. A combination of antibiotics and probiotics seems to improve eradication rates primarily by decreasing side effects, resulting in increased adherence.

Another possible alternative to current therapy are DNA vaccines. DNA vaccines are constructed by inserting DNA encoding a pathogen's antigen into a bacterial plasmid, thus inducing both humoral and cellmediated immunity (36). A recent study by Sun et al (37) has shown a protective effect of DNA vaccines on $H$ pylori infection in mice. In addition, vaccination to both prevent and treat infection appears to be a very cost-effective alternative in $H$ pylori treatment (38).

Monotherapy with bovine antibodies may not be the optimal alternative to current eradication therapies. Recent studies have described positive effects of combination therapy, for example, the addition of Lactobacillus to the current standard treatment. Such a positive effect could also be expected from adding WPC- 80 to current eradication therapies. This adjunct to antibiotic therapy requires further investigation while the search for alternatives continues. The prevention of $H$ pylori infection is a subject of interest, particularly in the developing world and could be another focus of research, especially because this effect has been described in vitro (15).

Due to increases in the current failure rates of antibiotic-based eradication therapy, the goal of future immunotherapy should focus on replacing antibiotic-based treatment entirely, instead of searching for adjunctive therapies. Presently, the most hopeful alternatives are preventive or therapeutic vaccination therapy. A recent study (39) demonstrated the cost-effectiveness of preventive vaccination in children.

\section{REFERENCES}

1. Goodwin CS, Mendall MM, Northfield TC. Helicobacter pylori infection. Lancet 1997;349:265-9.

2. Kuipers EJ, Uyterlinde AM, Pena AS, et al. Long-term sequelae of Helicobacter pylori gastritis. Lancet 1995;345:1525-8.

3. Kusters JG, van Vliet AH, Kuipers EJ. Pathogenesis of Helicobacter pylori infection. Clin Microbiol Rev 2006;19:449-90.

4. Malfertheiner P, Megraud F, O'Morain C, et al. Current concepts in the management of Helicobacter pylori infection: The Maastricht III Consensus Report. Gut 2007;56:772-81.

5. Fischbach LA, van Zanten S, Dickason J. Meta-analysis: The efficacy, adverse events, and adherence related to first-line anti-Helicobacter pylori quadruple therapies. Aliment Pharmacol Ther 2004:20:1071-82.

6. Gerrits MM, van Vliet AH, Kuipers EJ, et al. Helicobacter pylori and antimicrobial resistance: Molecular mechanisms and clinical implications. Lancet Infect Dis 2006;6:699-709.

7. Davidson GP, Whyte PB, Daniels E, et al. Passive immunisation of children with bovine colostrum containing antibodies to human rotavirus. Lancet 1989;2:709-12.

8. Mitra AK, Mahalanabis D, Ashraf $\mathrm{H}$, et al. Hyperimmune cow colostrum reduces diarrhoea due to rotavirus: A double-blind, controlled clinical trial. Acta Paediatr 1995;84:996-1001.

9. Tollemar J, Gross N, Dolgiras N, et al. Fungal prophylaxis by reduction of fungal colonization by oral administration of bovine anti-Candida antibodies in bone marrow transplant recipients. Bone Marrow Transplant 1999;23:283-90.

10. Torres O, Cruz JR. Protection against Campylobacter diarrhea: Role of milk IgA antibodies against bacterial surface antigens. Acta Paediatr 1993;82:835-8.

11. van Dissel JT, de Groot N, Hensgens CM, et al. Bovine antibodyenriched whey to aid in the prevention of a relapse of Clostridium difficile-associated diarrhoea: Preclinical and preliminary clinical data. J Med Microbiol 2005;54:197-205.

12. Casswall TH, Nilsson HO, Bjorck L, et al. Bovine anti-Helicobacter pylori antibodies for oral immunotherapy. Scand J Gastroenterol 2002;37:1380-5.

13. Marnila P, Rokka S, Rehnberg-Laiho L, et al. Prevention and suppression of Helicobacter felis infection in mice using colostral preparation with specific antibodies. Helicobacter 2003;8:192-201.
A recent review article (40) reported that $H$ pylori vaccination prevents, reduces and eliminates $H$ pylori infection in animal models, and that vaccines based on multiple virulence factors cure and prevent infection. A phase I study with a vaccine based on virulence factors in healthy volunteers (39) demonstrated a strong antibody response and was well tolerated, and currently appears to be the most promising alternative for $\mathrm{H}$ pylori treatment. Unfortunately, significantly more funding and research is needed before this particular alternative treatment is fully developed.

\section{CONCLUSION}

Monotherapy with bovine antibody-based oral immunotherapy does not reduce intragastric $H$ pylori bacterial load, nor does it have an effect on $H$ pylori-associated gastritis. However, WPC-80 is well tolerated and does not cause any adverse effects, nor does it have a negative influence on quality of life scores. Further research into the possible use of WPC-80 as a supplement to current eradication regimens is necessary.

ACKNOWLEDGEMENTS: This study was designed and conducted to meet internationally accepted ethical standards and complies with the CONSORT statement. The authors acknowledge Muco Vax BV, Leiden, the Netherlands and DMV International, Veghel, The Netherlands, for the development of the platform technique and the production of the immune WPC-80 preparation and the placebo.

DISCLOSURE: This study was funded, in part, by Muco Vax BV, Leiden, The Netherlands.
14. Thomas JE, Austin S, Dale A, et al. Protection by human milk IgA against Helicobacter pylori infection in infancy. Lancet 1993;342:121.

15. Weiner C, Pan Q, Hurtig M, et al. Passive immunity against human pathogens using bovine antibodies. Clin Exp Immunol 1999;116:193-205.

16. Casswall TH, Sarker SA, Albert MJ, et al. Treatment of Helicobacter pylori infection in infants in rural Bangladesh with oral immunoglobulins from hyperimmune bovine colostrum. Aliment Pharmacol Ther 1998;12:563-8.

17. Oona M. Helicobacter pylori in children with abdominal complaints: Has immuni bovine colostrum some influence on gastritis? Alpe Adria Microbiol J 1997;6:49-57.

18. Opekun AR, El-Zaimaity HM, Osato MS, et al. Novel therapies for Helicobacter pylori infection. Aliment Pharmacol Ther 1999;13:35-42.

19. Ando KN, T. A method for producing a new medicine for both treating and preventing peptic ulcer diseases and gastritis and thus formulated medicines. European Patent Office 1991:1-14.

20. Tarpila SK, H. Immune colostrum in the treatment of Helicobacter pylori gastritis. 24th Int Diary Congress. Melbourne, Australia: Brief Communications 1994:293.

21. Dimenas E, Glise H, Hallerback B, et al. Quality of life in patients with upper gastrointestinal symptoms. An improved evaluation of treatment regimens? Scand J Gastroenterol 1993;28:681-7.

22. Dimenas E, Glise H, Hallerback B, et al. Well-being and gastrointestinal symptoms among patients referred to endoscopy owing to suspected duodenal ulcer. Scand J Gastroenterol 1995;30:1046-52.

23. Cats A, Kuipers EJ, Bosschaert MA, et al. Effect of frequent consumption of a Lactobacillus casei-containing milk drink in Helicobacter pylori-colonized subjects. Aliment Pharmacol Ther 2003;17:429-35.

24. Clyne M, Thomas J, Weaver L, et al. In vitro evaluation of the role of antibodies against Helicobacter pylori in inhibiting adherence of the organism to gastric cells. Gut 1997;40:731-8.

25. Early EM, Hardy H, Forde T, et al. Bactericidal effect of a whey protein concentrate with anti-Helicobacter pylori activity. J Appl Microbiol 2001;90:741-8. 
26. Shin JH, Yang M, Nam SW, et al. Use of egg yolk-derived immunoglobulin as an alternative to antibiotic treatment for control of Helicobacter pylori infection. Clin Diagn Lab Immunol 2002;9:1061-6.

27. Suzuki H, Nomura S, Masaoka T, et al. Effect of dietary anti-Helicobacter pylori-urease immunoglobulin Y on Helicobacter pylori infection. Aliment Pharmacol Ther 2004;20 Suppl 1:185-92.

28. Dial EJ, Hall LR, Serna H, et al. Antibiotic properties of bovine lactoferrin on Helicobacter pylori. Dig Dis Sci 1998;43:2750-6.

29. Okuda M, Nakazawa T, Yamauchi K, et al. Bovine lactoferrin is effective to suppress Helicobacter pylori colonization in the human stomach: A randomized, double-blind, placebo-controlled study. J Infect Chemother 2005;11:265-9.

30. Huynh HQ, Campbell MA, Couper RT, et al. Lactoferrin and desferrioxamine are ineffective in the treatment of Helicobacter pylori infection and may enhance $H$ pylori growth and gastric inflammation in mice. Lett Appl Microbiol 2009.

31. Zou J, Dong J, Yu XF. Meta-analysis: The effect of supplementation with lactoferrin on eradication rates and adverse events during Helicobacter pylori eradication therapy. Helicobacter 2009;14:119-27.

32. Armuzzi A, Cremonini F, Bartolozzi F, et al. The effect of oral administration of Lactobacillus GG on antibiotic-associated gastrointestinal side-effects during Helicobacter pylori eradication therapy. Aliment Pharmacol Ther 2001;15:163-9.

33. Canducci F, Armuzzi A, Cremonini F, et al. A lyophilized and inactivated culture of Lactobacillus acidophilus increases Helicobacter pylori eradication rates. Aliment Pharmacol Ther 2000;14:1625-9.

34. de Bortoli N, Leonardi G, Ciancia E, et al. Helicobacter pylori eradication: A randomized prospective study of triple therapy versus triple therapy plus lactoferrin and probiotics. Am J Gastroenterol 2007;102:951-6.

35. Sachdeva A, Nagpal J. Effect of fermented milk-based probiotic preparations on Helicobacter pylori eradication: A systematic review and meta-analysis of randomized-controlled trials.

Eur J Gastroenterol Hepatol 2009;21:45-53.

36. Herrmann JE. DNA vaccines against enteric infections. Vaccine 2006;24:3705-8.

37. Sun B, Li ZS, Tu ZX, et al. Construction of an oral recombinant DNA vaccine from $H$ pylori neutrophil activating protein and its immunogenicity. World J Gastroenterol 2006;12:7042-6.

38. Agarwal K, Agarwal S. Helicobacter pylori vaccine: From past to future. Mayo Clin Proc 2008;83:169-75.

39. Malfertheiner P, Schultze V, Rosenkranz B, et al. Safety and immunogenicity of an intramuscular Helicobacter pylori vaccine in noninfected volunteers: A phase I study. Gastroenterol 2008;135:787-95.

40. Velin D, Michetti P. Advances in vaccination against Helicobacter pylori. Expert Rev Gastroenterol Hepatol 2010;4:157-66.

41. Rokkas T, Sechopoulos P, Robotis I, et al. Cumulative H. pylori eradication rates in clinical practice by adopting first and second-line regimens proposed by the Maastricht III consensus and a third-line empirical regimen. Am J Gastroenterol 2009;104:21-5.

42. Hojo M, Miwa H, Nagahara A, et al. Pooled analysis on the efficacy of the second-line treatment regimens for Helicobacter pylori infection. Scand J Gastroenterol 2001;36:690-700.

43. Seppälä K, Kosunen TU, Nuutinen H, et al. Cure of Helicobacter pylori infection after failed primary treatment: One-center results from 120 patients. Scand J Gastroenterol 2000;35:929-34.

44. Pontone S, Standoli M, Angelini R, et al. Efficacy of H. pylori eradication with a sequential regimen followed by rescue therapy in clinical practice. Dig Liver Dis 2010;42:541-3.

45. Kearney DJ, Brousal A. Treatment of Helicobacter pylori infection in clinical practice in the United States: Results from 224 patients. Dig Dis Sci 2000;45:265-71.

46. Vaira D, Zullo A, Vakil N, et al. Sequential therapy versus standard triple-drug therapy for Helicobacter pylori eradication: A randomized trial. Ann Intern Med 2007;146:556-63. 


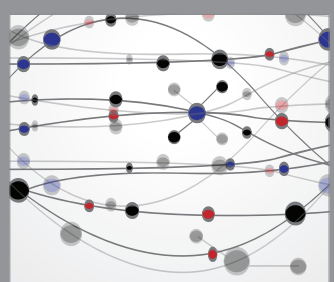

The Scientific World Journal
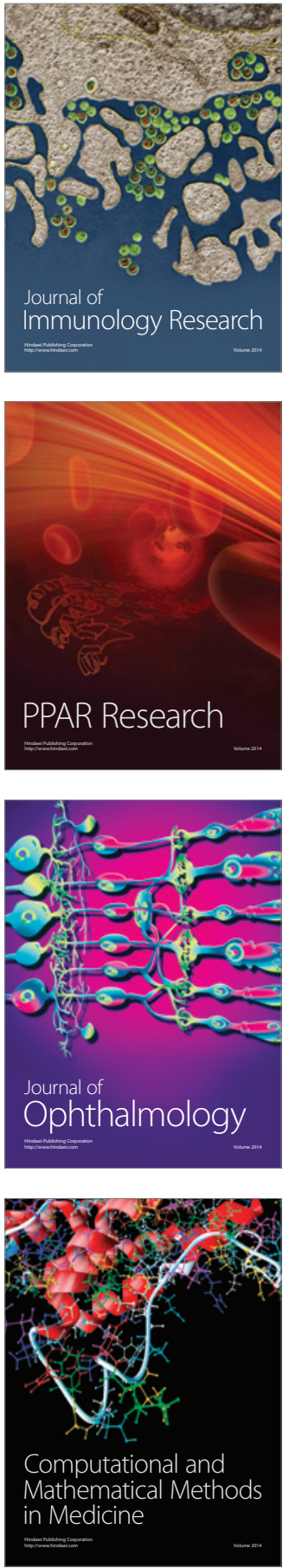

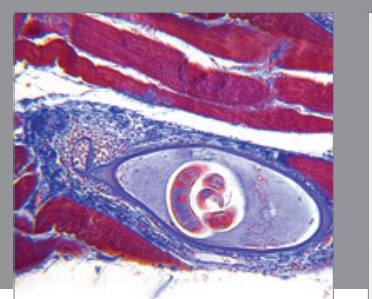

Gastroenterology Research and Practice

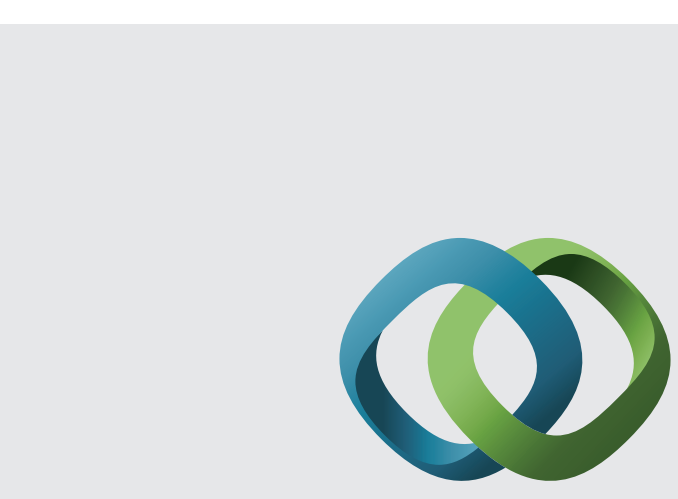

\section{Hindawi}

Submit your manuscripts at

http://www.hindawi.com
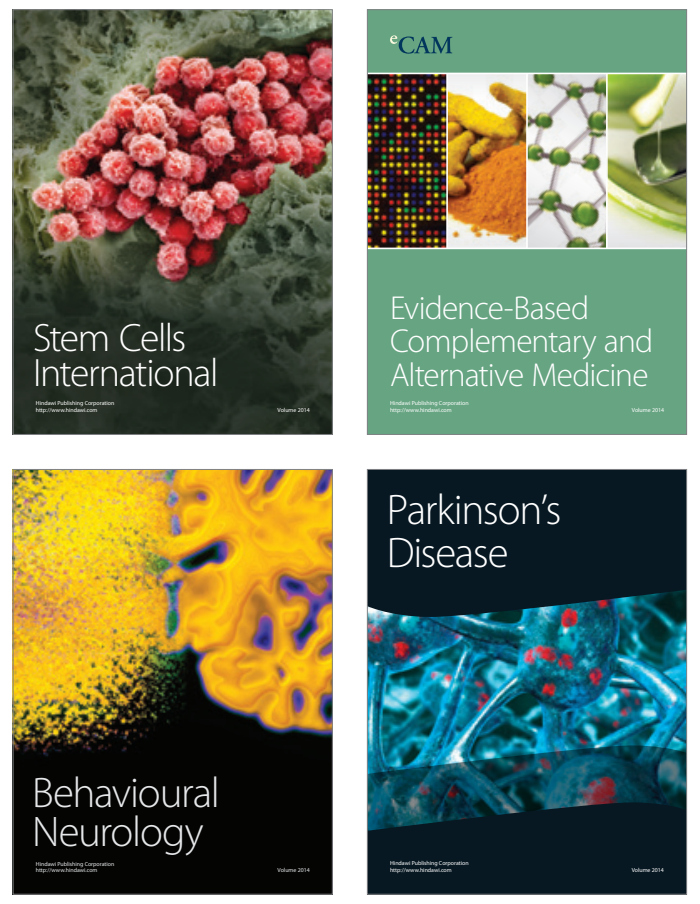
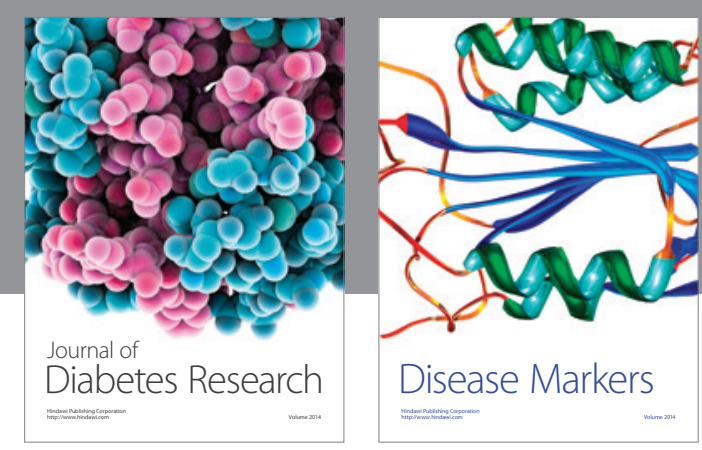

Disease Markers
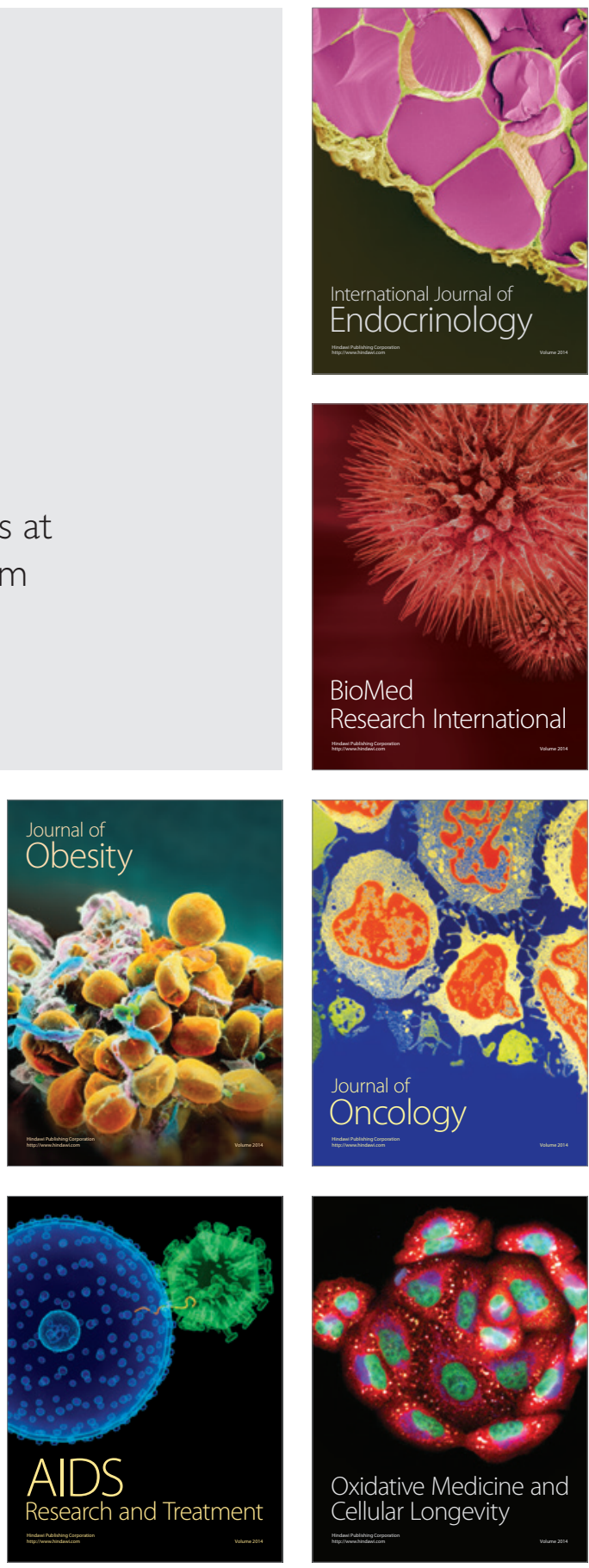